\title{
8. Adding new scopes to traditional EQA schemes emphasizing Quality Improvement
}

\author{
E. Olafsdottir ${ }^{1}$, K. Hellsing ${ }^{2}$, H. Steensland ${ }^{3}$, \\ R. Tenhunen ${ }^{4}$, A. Uldall 5 \\ ${ }^{1}$ Department of Clinical Chemistry, Landspitalinn, 101 Reykjavik, Iceland \\ ${ }^{2}$ Department of Clinical Chemistry, University Hospital, S-75185 Uppsala, Sweden \\ ${ }^{3}$ Department of Clinical Chemistry, Ullevål Hospital, N-0456 Oslo, Norway \\ ${ }^{4}$ Labquality, Stationskarlsgatan 4A, SF-00520 Helsinki, Finland \\ ${ }^{5}$ Department of Clinical Chemistry, Herlev University Hospital, DK-2730 Herlev, Denmark
}

The Nordic organizers of external quality assessment (EQA) schemes have taken a broader view of the objectives of such schemes than most traditional EQA organizers, as is well illustrated by a number of Nordic quality related projects referred to below. The Nordic EQA organizers feel an obligation to support actively quality improvements according to needs of the laboratories. Improved analytical specificity and standardization of analytical methods should become an integral part of EQA schemes, changing the emphasis from assessing the quality of analytical work to assuring quality by external guidance through external quality assurance (EQAssur) schemes. In preparation of such a change the following elements have to be considered:

\section{(i) Establishment of quality goals and desirable performance standards}

Following the initial Nordic Clinical Chemistry Project (NORDKEM) where quality requirements were assessed (1) it was recommended that each laboratory set their own quality goals and desirable performance standards. In 1989 the Nordic Federation of Clinical Chemistry (NFKK) issued recommendations stating in six paragraphs the essential steps to be taken to improve overall quality in the analytical work (2). How to set quality goals is still a matter of discussion since various approaches are possible and different situations call for different quality demands. The most logical approach would be to set quality goals according to medical needs (3), this however is often difficult since the necessary data are still available for only a limited number of analytes. Others have argued that quality goals should be based on biological variation (4) where 
data are not available to set goals otherwise. The biological variation approach to goal setting is simple and therefore possibly more likely to be accepted by many laboratory directors (5). The medical need will ultimately be the goal in many settings, since different quality may be required for analysis performed for screening purpose, diagnosis, following treatment or recovery etc. Labquality is presently working on goal setting based on the principles of biological variation (4) and the "state of the art" today.

\section{(ii) Assessment of the overall analytical performance}

The first Nordic survey of the clinical chemistry was published in 1970 (6) reporting the "state of the art" at that time. Since then several limited Nordic surveys have been run by different members of Nordic Clinical Chemistry, assessing specific areas within the field each time. The longstanding work of Labquality in Finland has thoroughly recorded and published quality performance in Finnish laboratories as well as some more selected fields in other Nordic laboratories. National and regional EQA in Denmark, Norway and Sweden have good records of laboratory performance in the last two decades.

Recently Norway and Sweden have changed their EQA operation considerably. In Norway the hospital laboratories have joined Labquality and EQA outside hospitals is in the hands of NOKLUS (Norsk senter for kvalitetssikring av laboratorieanalyser utenfor sykehus). In Sweden the newly established SEQLA (Swedish External Quality Assurance in Laboratory Medicine) organizes EQA in all fields of laboratory medicine, and concurrently Nordic co-operation in the EQA field has been reinforced with the establishment of NQLM (Nordic External Quality Assurance Programs in Laboratory Medicine).

(iii) Conducting specialized EQAssur programs, where specific analytical pitfalls are studied

EQAssur programs are very useful to sort out methods and instruments that are not giving satisfactory performance and can thus be used as an additional way of correcting analytical problems which have been suspected or detected as poor performers by other means $(7,8)$. It must however be stressed that poor calibrators, poorly kept instruments, reagents and errors in method performance must be ruled out when EQAssur programs are used to screen for nonspecific or poorly performing instruments/methods. 
Metrological recommendations $(9,10)$ and use of relevant calibrators $(11,12,13)$ have been developed as a result of unacceptable performance in EQA schemes. In 1974-76 recommendations of the Scandinavian Committee on Enzymes were published $(10,14)$ and shortly afterwards most Nordic laboratories converted to the new methods for the four enzymes in blood, ALAT, ASAT, GT and CK. In 1990 it was recommended that all laboratories in the Nordic countries changed over to the ECCLS methods (15) for these particular enzymes and most did so. The latest recommendation is to change over to a common protein calibrator, the BCR CRM 470, in all Nordic laboratories performing protein analysis before the end of 1994.

\section{(v) Assessment of quality improvement using EQA schemes or PT*}

EQA schemes could be used to register quality improvements in analytical areas where such improvement is considered particularly important. This has been demonstrated in a number of surveys on protein analysis in the Nordic countries (16). The first one carried out in 1977 revealed an unacceptable inter-laboratory variation.

Later in a NORDKEM sponsored Protein Project (17) where the elements of quality policy, quality improvement and quality control were combined a most striking results in quality improvement were observed. In the Protein Project the use of common calibrator was linked to an EQA scheme and this combination resulted in a significant improvement in performance of the participating laboratories (18). By linking the protein calibrator directly to the newly released IFCC/CAP/BCR CRM 470 protein standard a true target value for protein analysis is set. The Protein Project also included turbid material in order to signal out methods sensitive to interferences. This is in accord with the above mentioned philosophy and will be looked upon as a leading example in widening the scope of EQA schemes.

(vi) Supporting internal quality control continuously by specially designed EQAssur* programs

In Denmark and Finland the National EQA schemes have successfully been used to support continuously the internal QC programs of many laboratories $(19,20$, 21). The Danish Society of Clinical Chemistry has distributed quality control ma- 
terial to its members for use in internal QC, the "K-series" and used that as basis for the National EQA scheme, thus interlinking internal and external quality control. Labquality has provided similar services by its longterm EQAs, where the same control material is distributed over a long time period (20).

(vii) Monitoring the methods and the laboratory performance through a simplified EQA scheme using detailed information about methods

A novel use of EQA schemes is to monitor the performance of methods when detailed information about the method protocols is available. The coming EC-Directive on in-vitro diagnostic products seems to advocate using this approach for supplementing market surveillance of essential in-vitro diagnostic products.

(viii) Proper action taken by the laboratory when deviating findings occur

In EQA schemes suited for laboratory licensing or accreditation the emphasis should not only be on performance criteria for reported results, but also on the correct action taken by the laboratory when deviating findings occur.

Guidelines for acceptance of proficiency testing programs have been issued by WELAC (22). According to these proficiency testing should "demonstrate and monitor competence of the laboratory to carry out specific tests or analyses". It is however of utmost importance to incorporate into written protocols for daily maintainance of quality, the actions taken by the laboratory when deviating findings do occur (23).

(ix) Promote the establishment of common reference intervals where relevant

In a health care systems where patients are frequently being referred from the family doctor to a specialist or from one hospital to another transferability of clinical chemistry results and common reference intervals are of importance in providing a safer, faster and less expensive service to the patient. All scientific work on patients' results becomes more reliable and meaningful if this becomes a realization. Recently thorough and extensive work has been done on establishing common reference intervals for plasma proteins for the Nordic Population (24). A foreseen difficulty with common reference intervals for plasma proteins has to be overcome when some laboratories start using substance concentrations instead of the now commonly used $g / L$ units for proteins. 
Well founded reference intervals are certainly a quality aspect of laboratory results. As such they fall within the scope of EQAssur programs. However it is debatable whether the establishment of common reference intervals for homogeneous populations should be a project attempted by EQA organizers. Such a project is today a task to be undertaken by collaboration of several laboratories with a support of well designed EQAssur programs.

\section{(x) Promote the use of modern nomenclature and units}

In accordance with other European EQA schemes the Nordic countries have promoted the use of modern nomenclature and SI units (25). Still there are problems to be solved under this heading, such as the use of molar quantities for proteins. The board of the Danish Society of Clinical Chemistry has recommended the use of molar units for proteins based on the most likely molecular masses.

The use of katal for expressing enzyme activities was adopted in Sweden, but the other Nordic countries still hold on to the international units (IU) for enzyme activities. Some laboratories have not converted over to SI units for drugs and nomenclature is still to be adapted to officially agreed vocabulary in many areas. The EQA organizers will however continue their educational role in promoting the issue and encourage discussions about the issues under dispute hopefully until consensus is reached.

The proficiency testing in Europe and the USA have been reviewed in Libeer's book on External Quality Assessment in Clinical Laboratories (26). The fundamental differences are in the professional and educational support given in the European EQAs versus the requirements of fulfilling minimum standards set by the Clinical Laboratory Improvement Act of the US Congress. The Nordic EQA-organizers participate in the increased European cooperation among their colleagues and have given the educational purpose of EQAssur a strong support.

*Note: External quality assurance (EQAssur) seems to be a better term than external quality assessment in the context of quality improvement program. The latter term may be substituted with the designation "proficiency testing" (PT) according to ISO nomenclature (27). 


\section{Correspondance to}

Elin Olafsdottir

Department of Clinical Chemistry

Landspitalinn

101 Reykjavik, Iceland or

\author{
Adam Uldall \\ Department of Clinical Chemistry \\ Herlev University Hospital \\ DK-2730 Herlev, Denmark
}

\section{References}

1. Hørder M (ed.) Assessing quality requirements in clinical chemistry. The Nordic Clinical Chemistry Project (NORDKEM). Scand J Clin Lab Invest 1980;40,suppl 155:1-144.

2. Scandinavian Society for Clinical Chemistry. General Scandinavian recommendations on quality control and quality assurance in clinical chemistry. Scand J Clin Lab Invest 1990;50:225-7.

3. deVerdier C.-H. (ed) Medical Need for Quality Specifications in Laboratory Medicine. A NORDKEM Project 1989-1992. + Uppsala J Med Sci 1990:95;162-309.

4. Fraser CG, Hyltoft Petersen P. Quality goals in external quality assessment are best based on biology. Scand J Clin Lab Invest 1993;53 suppl 612:8-9.

5. Hyltoft Petersen P, Groth T, deVerdier C-H. Principles for assessing analytical quality specifications ("AQSpecs") and their use in design of control systems. Upsala d Med Sci 1993;98:195-214.

6. Strömme JH, Eldjarn L. Surveys of the routine work of clinical chemical laboratories in 116 Scandinavian hospitals. Scand J Clin Lab Invest 1970;25:213-22.

7. Uldall A, Fogh-Andersen N, Thode J et al. Measurement of ionized calcium with five types of instruments. An external quality assessment. Scand J Clin Lab Invest 1985;45:255-61.

8. Hyltoft Petersen P, Blaabjerg O, Irjala K, Icén A, Bjøro K. A model for quality achievement - the NORDKEM protein project. Scand $J$ Clin Lab Invest 1993;53, suppl 212:10-2.

9. Uldall A, Improvements in the routine investigations of urinary calculi. Scand $J$ Clin Lab Invest 1984;44, suppl 172:147-56.

10. Keiding R, Hørder M, Gerhardt W et al. Recommended methods for the determination of four enzymes in blood. Scand J Clin Lab Invest 1974;33:287-396.

11. Gerhardt W, Waldenström J, Hørder M et al. SCE Nordic Alpha-amylase study. 1: method selection and calibration study. II: Assessment of proposed calibration procedure. Scand $J$ Clin Lab Invest 1985;45:397-404. Ibid. 1986;46.465-9.

12. Raabo E, Kynde K, Sandberg-Hansen M. Evaluation of a calibrator used for ISC-calibration of coagulation tests in Denmark. EQAnews 1992;3 no 2:4.

13. Blaabjerg O, Blom M, Gry H, Hyltoft Petersen P, Uldall A. Appropriate sera for calibration and control of specific protein assays. Scand J Clin Lab Invest 1993;53,suppl 212:13-5.

14. Scandinavian Committee on Enzymes. Recommended method for the determination of gammaglutamyltransferase in blood. Scand J Clin Lab Invest 1976;36:119-25.

15. ECCLS Standards for Enzyme Determination. Klinisk kemi i Norden 1990;2 suppl.

16. Carlström A, Gävert J, Hellsing $\mathrm{K}$ et al. Improvement of Quality of Protein. Analysis in Nordic Countries - a Comparative Study. 
17. Hyltoft Petersen P, Blaabjerg O, Irjala K, Icén A, Bjøro K. A model for quality achievement - the NORDKEM protein project. Scand J Clin Lab Invest 1993;53 suppl. 212:10-2.

18. Gry H, Blaabjerg O, Blom M, Uldall A, Hyltoft Petersen P. Preparation of a protein calibrator. Scand J Clin Lab Invest 1988;48 suppl. 190:157.

19. Blom M, Brock A, Christensen $\mathrm{F}$ et al. External quality assessment pragrams in Denmark. Scand $J$ Clin Lab Invest 1984;44 suppl 172:175-8.

20. Grönroos et al. External quality assessment programs in Finland 1971-1983. Scand J Clin Lab Invest 1984;44 suppl 172:179-86.

21. Blaabjerg O, Elg P, Gerhardt W, Hellsing K, Olafsdottir E, Pentillä I, Hyltoft Petersen P, Steensland $\mathrm{H}$, Uldall A. A Nordic reference serum suitable for use as trueness control in the clinical routine laboratories. Upsala J Med Sci 1993;98:405-12.

22. WELAC. European Laboratory Accreditation Publication. ELA-G6. Welac Guidance Document WGD4. WELAC Criteria for Proficiency Testing in Accreditation. 1 ed. 1993-09:1-12.

23. Dybkær R, Jordal R, Jørgensen P J,Hansson P, Hjelm M, Kaihola H-L, Kallner A, Rustad P, Uldall $\mathrm{A}$, deVerdier $\mathrm{C}-\mathrm{H}$. A quality manual for the clinical laboratory including the elements of a quality system. Scand J Clin Lab Invest 1993;53 suppl. 212;60-84.

24. Blaabjerg O, Blom M, Gry $\mathrm{H}$ et al. Fælles Referenceintervaller i Norden for 9 Plasmaproteiner. Klinisk Kemi i Norden 1993;5 no 4:13-17.

25. Bullock D G, Libeer J C, Zender R. EQAnews 1994, vol 5 no 2:1-2.

26. Libeer J C. External Quality Assessment in Clinical Laboratories. European Perspective: Today and Tomorrow. 1993:635 pp. Universitaire sustellung Antwerpen.

27. ISO/IUPAC/AOAC. The international harmonized protocol for the proficiency testing of (chemical) analytical laboratories. Pure Appl Chem 1993;65:3-20. 
